\title{
Influence of the flexibility of beams and slabs in static response and dynamic properties
}

\section{Influência da flexibilidade de vigas e lajes na resposta estática e propriedades dinâmicas}
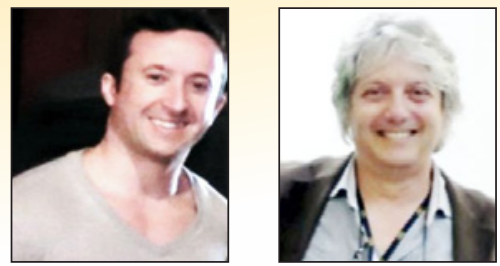

J. R. BUENO a,

jefersonrafael@utfpr.edu.br

D. D. LORIGGIO b

daniel.loriggio@ufsc.br

\begin{abstract}
This article examines numerically the flexibility influence of support beams in static response and dynamic properties of a symmetric plate formed by massive slabs of reinforced concrete in elastic linear regime, using the Finite Element Method. In the static response the variation of bending moments and displacements are evaluated, which depend on the relationship between the flexibility of the slab and the beam. The evaluation of dynamic properties is held in undamped free vibration, through which the vibration modes and the values of the natural frequencies is obtained, which are compared with the limits of the Brazilian standard code for design of concrete structures. Results show that the response may show great variation due to the change in the relationship between bending stiffness of the slabs and the beams.
\end{abstract}

Keywords: beams flexibility, massive slabs, static analysis, dynamic analysis.

\section{Resumo}

Neste artigo estuda-se numericamente a influência da flexibilidade de vigas de apoio na resposta estática e nas propriedades dinâmicas de um tabuleiro simétrico formado por lajes maciças e vigas de concreto armado, em regime elástico-linear, via Método dos Elementos Finitos. Na resposta estática a variação de momentos fletores e deslocamentos é avaliada, os quais dependem da relação entre a flexibilidade da laje e da viga. A avaliação das propriedades dinâmicas é realizada em vibração livre não amortecida, pela qual se obtêm os modos de vibração e os valores das frequências naturais que são comparadas com os limites da norma brasileira de projeto de estruturas de concreto. Os resultados mostram que a resposta apresenta grande variação devido à alteração da relação entre rigidez à flexão das lajes e vigas.

Palavras-chave: flexibilidade de vigas, lajes maciças, análise estática, análise dinâmica.

Federal Technological University of Paraná - UTFPR, Civil Engineering Academic Department, Campo Mourão, PR, Brazil;

Federal University of Santa Catarina - UFSC, Civil Engineering Department, Florianópolis, SC, Brazil. 


\section{Introduction}

The calculation of requested efforts on reinforced concrete plates is a task of great importance within the structural design of buildings, and under such perspective it is stressed the importance of considering the deformability and eccentricity between these structural elements. There are studies that evidence the need to consider the flexibility between the slabs and beams in static response, [1], [2], [3], [4], and the dynamic properties/response, [5], [6], [7], but what factors influence it? Is the accuracy of the results undermined by the non-consideration of those effects? Moreover, how can they be considered in a coupled analysis on the plate? Those are some pertinent points when you want to study the effect of the flexibility of the support beams in the analysis and design of slab panels. Due to the peculiarities of each project, the references mentioned leave some gaps on recommendations and practices in relation to the subject, which is due to the difficulty of foreseeing on a realistic way the behavior of the slab/beam, system, including the effect of flexibility and eccentricity between slab and beam, mainly using manual calculations [8]. However, there is a need for standardization and recommendations describing care, limits and practices for the calculation of plates consisting of reinforced concrete beams and slabs.

Therefore, the main objective of this article is to analyze the influence of the flexibility of beams and slabs in the static response and dynamic properties, for the design of reinforced concrete plates by means of the Finite Element Method (FEM).

\section{Method}

\subsection{Static analysis}

The static response of the plate, its efforts and displacements were obtained by means of linear analysis by using the SAP2000 software using FEM. The slab and beams displacements are elastic and the

\section{Figure 1 - Eccentricity between the axis of the beam and slab median plan}

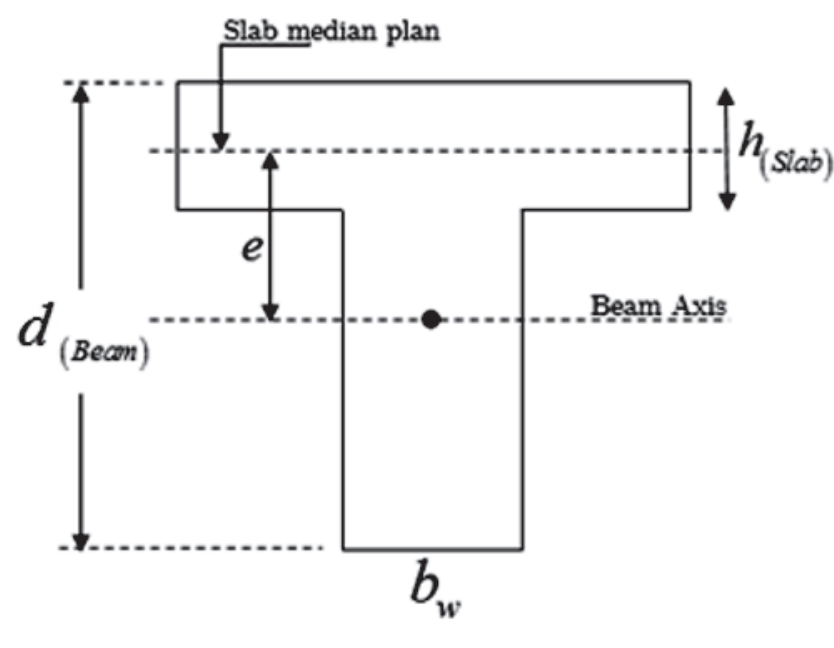

final displacement was calculated in accordance with NBR 6118 [9]. A plane model was used, where the slabs were modeled as finite quadrilateral elements of thin shell (Shell-Thin: 4 knots, 6 degrees of freedom per knot), based on the theory of Kirchhoff, that does not consider the transversal deformation due to shearing [10]. The beams were modeled as a frame, which considers in these tests only the deformation due to bending.

In this type of model, the axes of the beams and the shell elements are in the same plane. Initially, the models were used without consideration of eccentricity between the slab plane and the axis of the beams. This eccentricity causes the beam to have a conjunct behavior with the slab, increasing the rigidity of the set. A common model, in order to take into account this effect in projects, is to consider a T section for the beam. In this work the effect cited was incorporated into the model, thus increasing the inertia of the beam according to equation (1), as reference [3].

$$
I_{h e c m}=\frac{b_{11} d^{3}}{12}+b_{w} d e^{2}
$$

In the analysis when the moment of inertia of the cross section of the beam $(I)$ was changed, the resistant module and the radius of gyration were also changed. Some of the results are displayed using the index $I_{s b}$ that represents the flexibility coefficient between the slab and the beam, and is shown in equation (2) [2]. The objective of this coefficient is to present the results of this paper without showing the dimensions of the slab and the beam that were used.

$$
I_{s b}=\frac{I_{s}}{I_{b}}=\frac{\frac{h^{3} \sqrt{l_{x} l_{y}}}{12\left(1-v^{2}\right)}}{I_{b}}=\frac{h^{3}}{12 I_{b}} \frac{\sqrt{l_{x} l_{y}}}{\left(1-v^{2}\right)}
$$

Where $n$ is the Poisson coefficient, $I_{x}$ and $I_{y}$ are the slab dimensions in the $x$ and $y$ direction, respectively, where $I_{x}$ is the smallest value; $I_{s}$ is the slab flexibility index; $h$ is the thickness of the slab; and $I_{b}$ the flexibility index of the beam (which is equal to moment of inertia). Dimensionless indexes were used in order to present the moments result's $(\mathrm{kN} \cdot \mathrm{m} / \mathrm{m})$ independent of the thickness of the slabs [2], as show in equation (3), (4) and (5), where $q_{t}$ is the total load in slab. The use of these indexes allow a more comprehensive vision of the results, as it will be shown later.

$$
\text { Index to positive moment in the } x \text { direction: } \operatorname{Im}_{X}=\frac{q_{t}}{M_{X}} l_{x}{ }^{2}
$$

Index to positive moment I then $y$ direction: $\operatorname{Im}_{Y}=\frac{q_{t}}{M_{Y}} l_{x}^{2}$ 


$$
\text { Index to negative moment in the } x \text { direction: } \operatorname{Im}_{X e}=\frac{q_{t}}{M_{X e}} l_{x}^{2}
$$

The convention used in this work is that moments in a particular direction ( $x$ or $y$ ) are the ones who will provide armor in this same direction, $x$ and $y$ axes are shown in Figure 2. In the numerical analysis of this article, the following effects have not been checked/considered:

- Lifting of the edges of the slab in relation to its supports ("displacement" between slab and beam). The connection between the structural elements is considered as monolitic;

- Shearing in slabs and cracking of structural elements;

- The influence of the pillars section in the efforts of slabs and beams;

- Torsion stiffness of the support beams: this is only a compatibility rigidity, not being essential for the equilibrium of the plate.

\subsection{Dynamic proprieties}

The dynamic proprieties of the plate correspond to the natural frequencies and vibration modes, and were obtained with the FEM in which the problem of eigenvalues and eigenvectors is solved in undamped free vibration. The motion equation was obtained by $D$ 'Alembert's principle, equation (6), where $[M]$ is the lumped-mass matrix [10], $[K]$ is the matrix stiffness, $\{\ddot{u}\}$ is the vector of displacement and $\{\ddot{u}\}$ is the acceleration vector [11], [12].

$$
[M]\{u\}+[K]\{u\}=\{0\}
$$

The development of (6) leads to a polynomial equation of order $N$, with the roots $\omega_{n}$ called eigenvalues or characteristic values, and providing the $N$ circular frequencies $\omega_{\mathrm{n}}$ that can be sorted in ascending form being $\omega_{1}$ the smallest of them, known as circular fundamental frequency and harmonics higher than [12]. The displacement of the system can be obtained by a linear combination of vibration modes or eigenvectors. This property is used in a procedure called the modal analysis, constrained to structures with linear behavior [13], [14], [15].

To verify the influence of the response in each vibration mode, the modal participation factor ( $M p f)$ was considered, which indicates how strong each mode is excited by its respective acceleration loads [10]. In the plate, not always the vibration mode that has the lower frequency of vibration is the one that should be used, but rather the one that mo-

Table 1 - Critical frequency: structures subjected to vibrations by the action of people

\begin{tabular}{c|cc|}
\hline Use (Case) & $\begin{array}{c}\text { Critical firequency } \\
\mathbf{f}_{\text {ciit }}(\mathrm{Hz})\end{array}$ & $\begin{array}{c}\text { Fundamental } \\
\text { frequency } \\
\mathrm{f}_{1}\left(\mathrm{~Hz}_{\mathrm{z}}\right)\end{array}$ \\
\hline Office & 4.00 & 4.80 \\
Dance halls & 7.00 & 8.40 \\
\hline
\end{tabular}

bilizes more mass according to the direction of interest, which is the vertical direction or the global $Z$ axis in the cases under consideration. For a given vibration mode and a global reference axis, $X, Y$ or $Z$ , the modal participation factor is equal to the internal product (scalar product) of unitary acceleration along that axis and the vibration mode. To ensure a satisfactory behavior on the plate, a check of the excessive vibration state-limit was performed, in which the fundamental frequency of the structure $\left(f_{1}\right)$ in $\mathrm{Hz}$ unit, Table 1 , should stay as far as possible of the critical frequency $\left(f_{\text {crit }}\right)$, equation (7), according to NBR 6118 [9].

$$
f_{i}>1.2 f_{\text {crit }}
$$

For the lumped-mass matrix only the mass of elements given by multiplying the density by the volume was used. In the case of beams, the mass is grouped in the joints $i$ and $j$ (starting and ending node) and, for the slab's mass it is grouped in the element nodes [10]. Inertial effects are not considered along the elements.

\subsection{Plate characteristics}

a - Slab: Continuous and rectangular $(400 \times 600 \mathrm{~cm})$, Figure 2;

$b$ - Slab thickness: $h=10,12$ and $15 \mathrm{~cm}$;

$c$ - Board beams (rigid beams: $\mathrm{V}_{1}, \mathrm{~V}_{2}, \mathrm{~V}_{3}$ and $\mathrm{V}_{5}$ ): $15 \times 250 \mathrm{~cm}$;

$d$ - Intermediate Beam $V_{4}: b_{w}=15 \mathrm{~cm}$ and $d$ is variable, with $d_{\min }=15 \mathrm{~cm}$ and $d_{\max }=150 \mathrm{~cm}$. By variation of rigidity of this beam it was studied the influence of flexibility on the plate;

$e$ - The board beams have a rigid connection with the pillars (section $20 \times 20 \mathrm{~cm}$ ), and $V_{4}$ is supported by $V_{1}$ and $V_{2}$ with release of rotation;

$f$ - Resistance to compression of concrete: $f_{c k}=20 \mathrm{MPa}$;

$g$ - Secant modulus of elasticity: calculate by equation (8) where $\alpha_{\mathrm{e}}=1$ (granite):

$E_{c s}=0,8 E_{c i} \quad \therefore E_{c s}=0,8 \alpha_{e} 5600 \sqrt{f_{c k}}$

$h$ - Poisson coefficient: $v=20$;

i- FEM model: Slabs with a $12.5 \times 18.75 \mathrm{~cm}$ rectangular mesh (ratio between the dimensions of the slab) and pillars are represented as nodal points;

$j$ - Total load on slabs $q_{t}\left(\right.$ in $\left.k N / m^{2}\right): q_{t, h=10}=12.50$, $q_{t, h=12}=13, q_{t, h=15}=13.75$.

For each slab thickness (item $b$ ) an analysis with the variation of $\mathrm{V}_{4}$ beam dimensions was realized (item $d$ ) and so, the static response and the dynamic properties of the system obtained.

\section{Results And discussion}

\subsection{Static analysis}

For the general analysis of the results the values obtained on static response are displayed as a function of the dimensionless index, 
Figure 2 - Plate with continuous slab panel of equal slabs $(\mathrm{cm})$

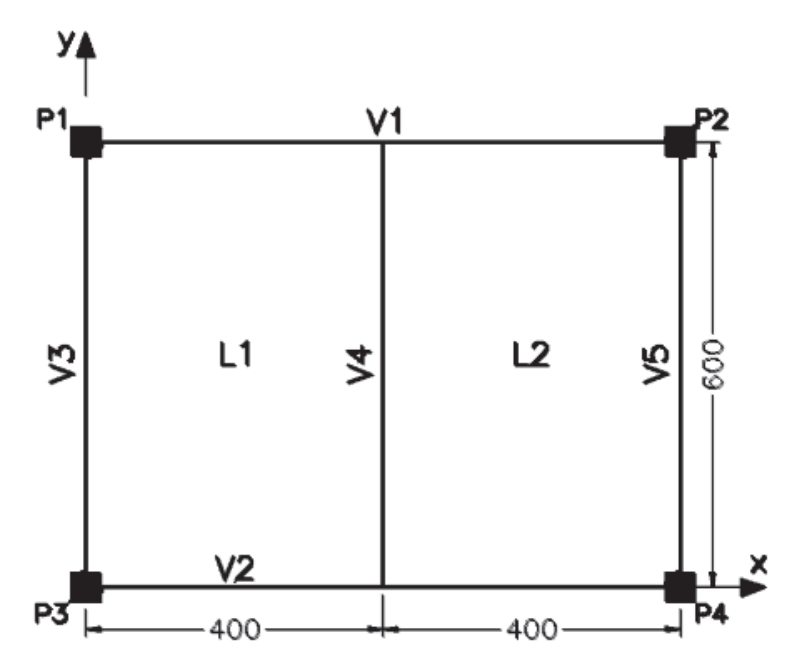

equation (2), generating a better visualization of the flexible behavior of the elements. Following, some explanations are made for reading and in order to enable a correct analysis of the figures. - $I_{v 4}=I_{\text {slab }} / I_{\text {beam v4 }}$ corresponds to the ratio between the flexibility of the $L_{1}$ slab with the flexibility of beam $V_{4}$. The higher the value of this index, the lower $\mathrm{V}_{4}$ beam height, and the lower its bending stiffness compared to the $L_{1}$ slab, i.e. with an increase of $d$, the $I_{v 4}$ index decreases, Figure 3;

- Legend for the figures: the terms " $h=10, h=12$ and $h=15 "$ correspond to the thickness of the slab for which the results are displayed.

- The results obtained with the consideration of eccentricity are presented with the description "[e]" in the caption of the figures, since other data refer to values without this consideration. The horizontal and/or vertical axis of some figures are displayed in logarithmic scale, base 2, so that trends and formations of technical analysis are clearer. In other cases, it is used in the linear scale. Figure 4 shows the results for the dimensionless indexes $\operatorname{Im}_{x}$ $\left(\operatorname{Im}_{x}[e]\right)$ and $\operatorname{Im}_{y}\left(\operatorname{Im}_{y}[e]\right)$ enabling a general analysis of the results, with easy viewing of the behavior of the variation of the efforts of the slab. It should be remembered that the indexes are inversely proportional to the bending moments, equation (3), (4) and (5). It is noted that it is possible to represent the results with just one curve, without having to display the values of $\boldsymbol{d}$ and $h$ of which the efforts are originated. The efforts obtained with consideration of [e] are smaller for displacements $\mathrm{M}_{\mathrm{x}}$ and $\mathrm{M}_{\mathrm{y}}$ and larger for $\mathrm{M}_{\mathrm{xe}}$ when compared to the computed values without this consideration. This behavior is related to the fact that, considering the " $e$ " results in a more rigid beam for the $\mathrm{V}_{4}$ support. The setting in which the support beam $V_{4}$ is more rigid is when you have the smallest thickness of slab due to greater eccentricity.

Figure 3 - Relationship between the height (d) of V4 beam and $\mathrm{I}_{\mathrm{v} 4}$ index

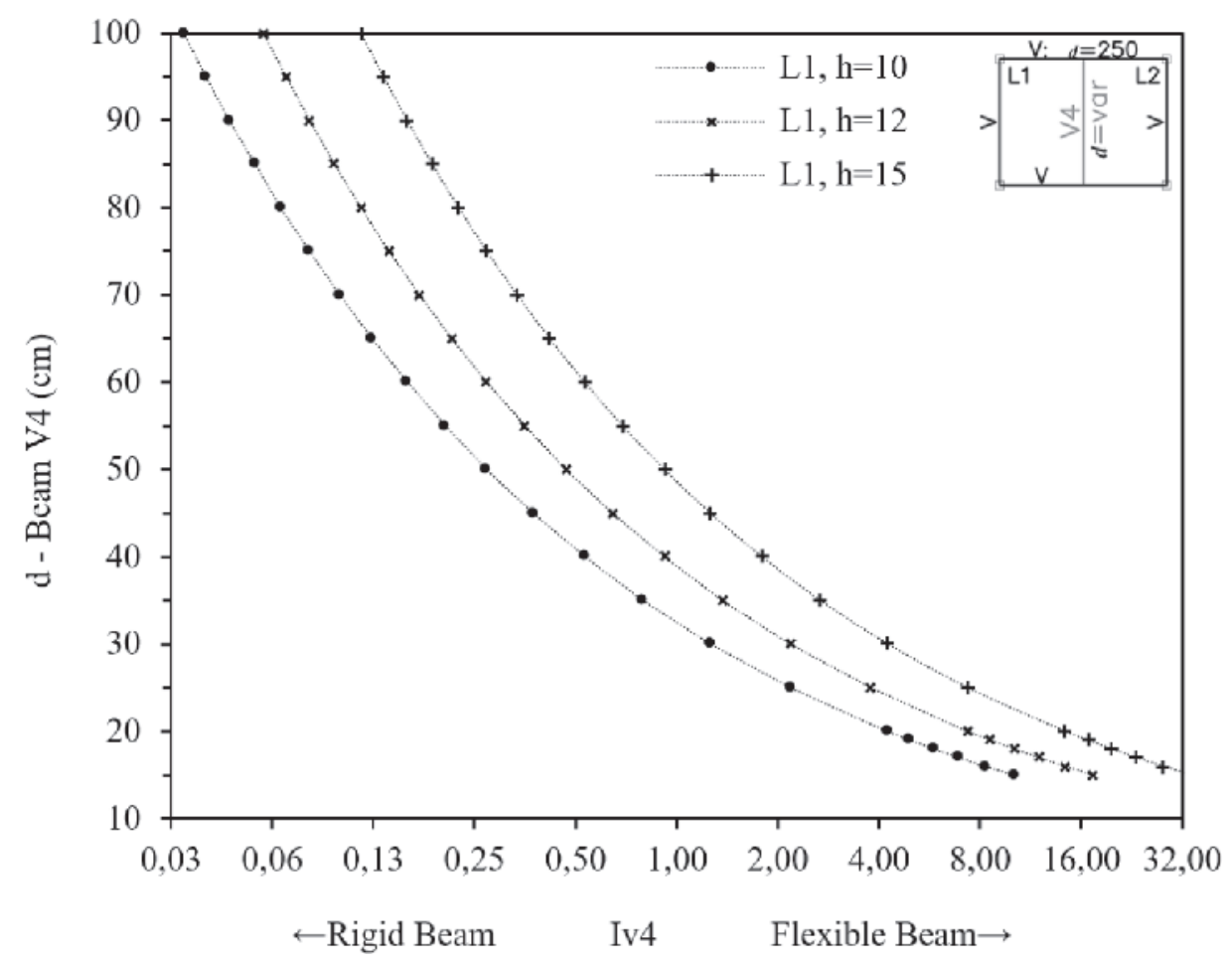


Figure 4 - Relationship: $\operatorname{Im}_{\mathrm{x}}, \operatorname{Im}_{\mathrm{y}}$ and $\mathrm{I}_{\mathrm{v} 4}$

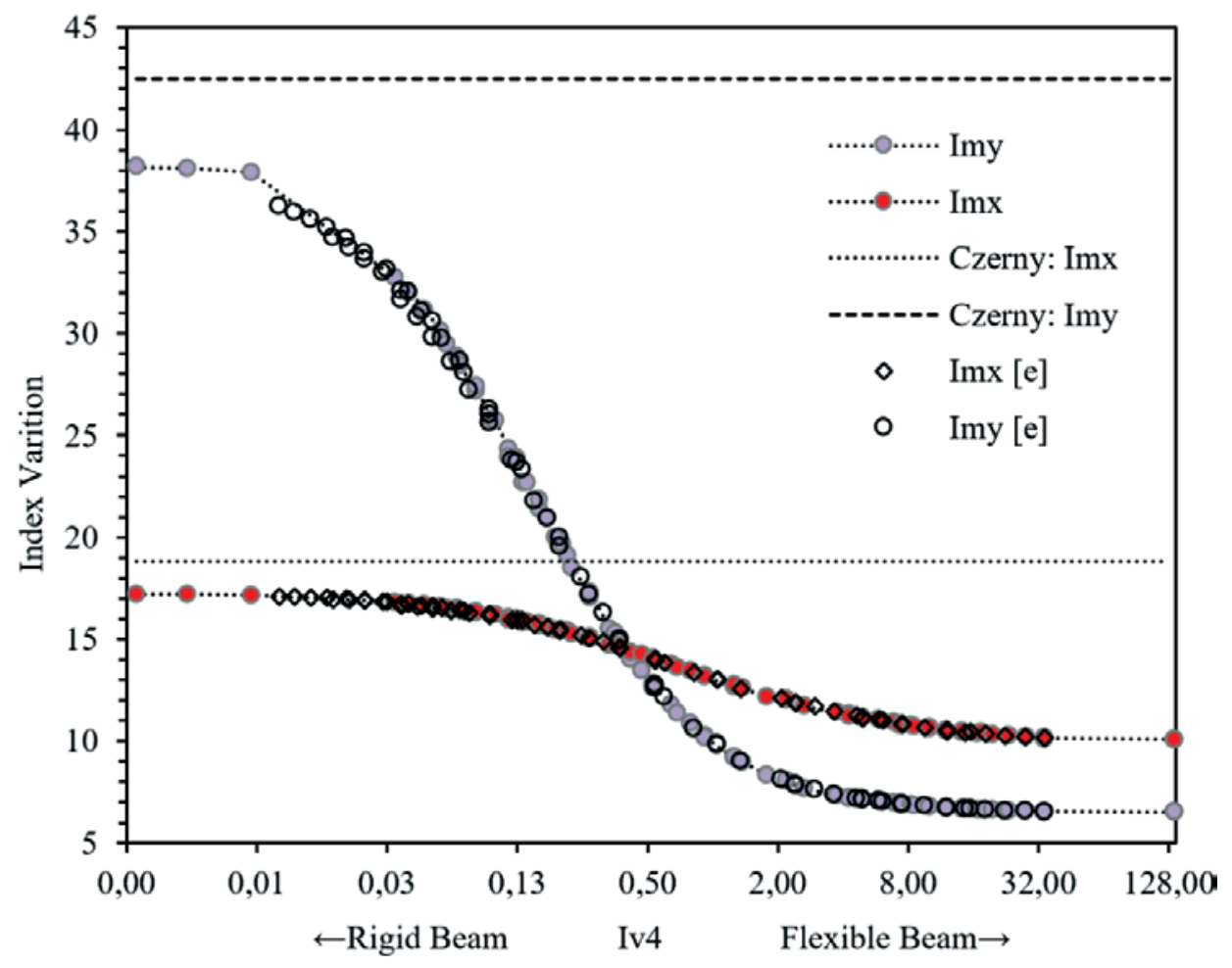

Figure $5-\operatorname{Im}_{x}$ and $\operatorname{Im}_{y}$ (Centre of $L_{1}$ for $I_{v 4} \neq 0.187$ )

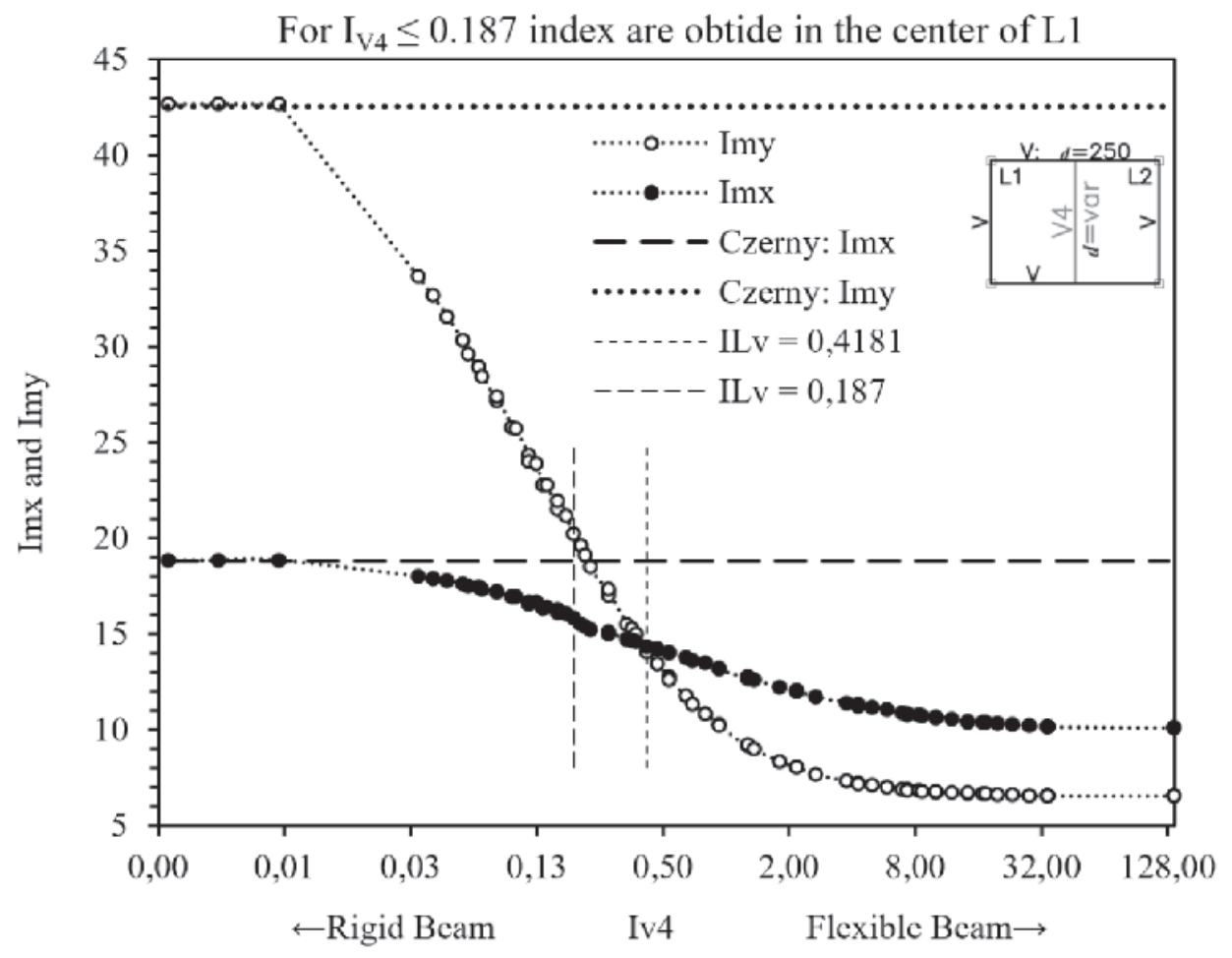




\section{Figure 6 - (a) FEM and Czerny relationship; (b) Imxe index}
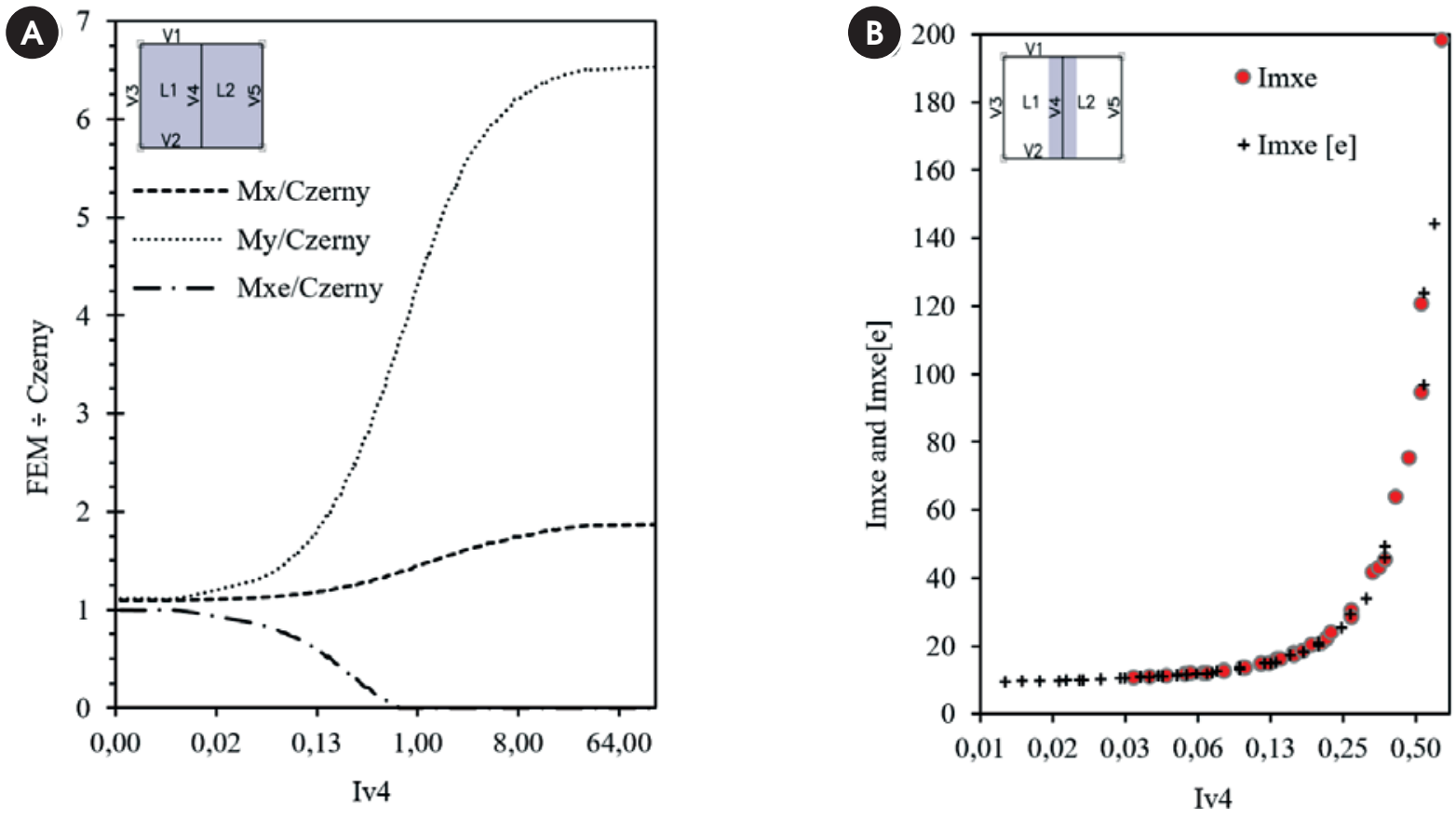

With the purpose of relating the difference between the consideration of the flexibility of supports with the manual calculation, the moments that would be obtained by using the Czerny tables for slabs are also presented, these indices being constant due to not considering the deformability of the slab. Therefore, Figure 4 and Figure 5 show that the difference between the results obtained by the FEM and the Czerny table can be significant, and that for the use of tables one must ensure that the support beams have significantly higher bending rigidity than the slab.

When $I L_{v 4}<0.4181$ the bending moment $\mathrm{M}_{\mathrm{x}}$ is bigger than $\mathrm{M}_{\mathrm{y}}$, i.e., the bending moment in the direction of the smallest length is greater than the moment in the direction of the greater length (of

Figure 7 - Non-uniform Variation of $M_{x e}$ to $h=12 \mathrm{~cm}$

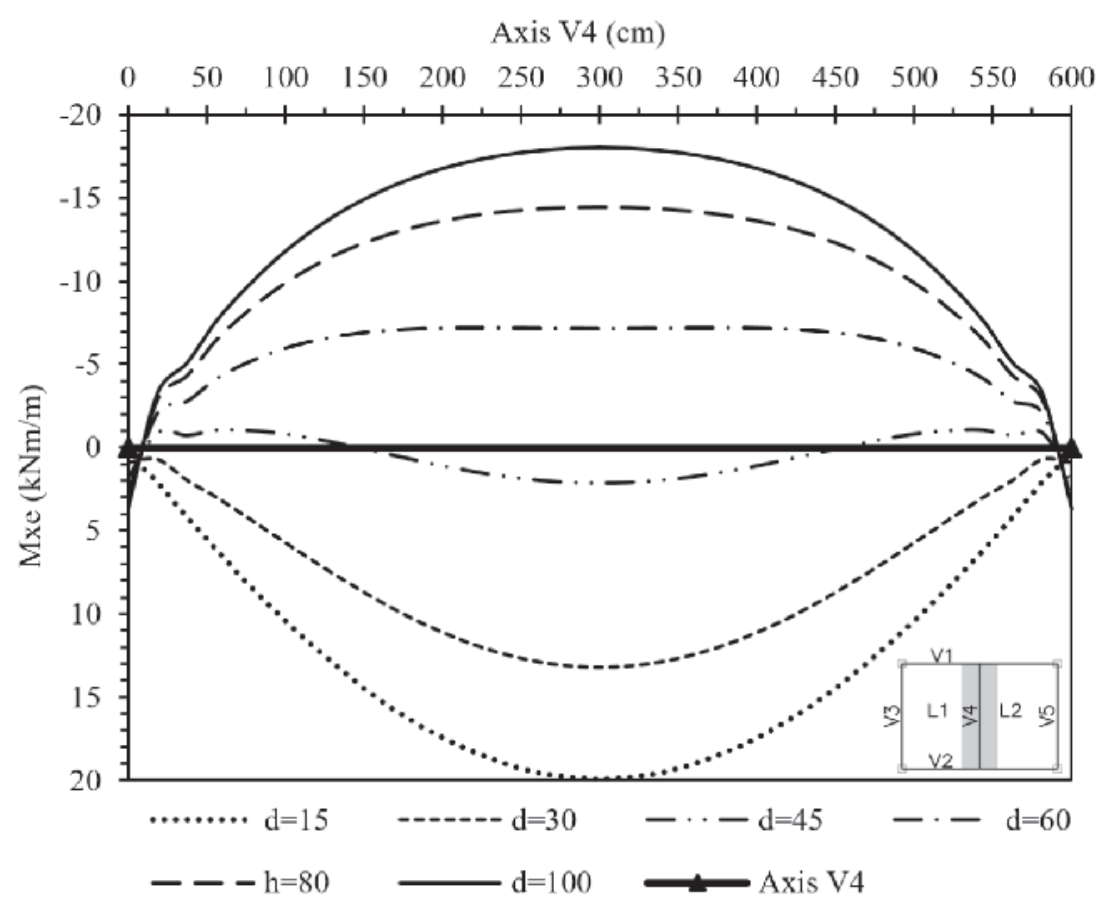


the slab). This behavior is consistent with the expected to the floor, once the slab tends to work in the direction of smallest length when the beam $V_{4}$ has enough stiffness. This same qualitative behavior is shown in the table results, where the supports are considered non-deformable. For $I_{v 4}>0.4181$ we have $M_{y}>M_{x}$, that is, the moment in the direction of greater length becomes greater than in the direction of the smaller length. Counteracting the traditional calculation with the use of tables, since the intermediate beam does not provide sufficient support.

The difference observed between the moments of the numerical

Figure 8 - Variation of efforts and displacements, $h=10 \mathrm{~cm}\left(\frac{\mathrm{kN} \cdot \mathrm{m}}{\mathrm{m}}\right.$ and $\left.\mathrm{cm}\right)$

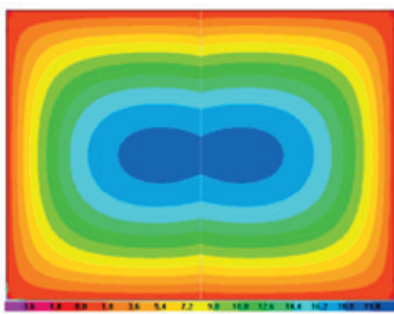

(a) $\mathrm{M}_{11}: \mathrm{d}=15$

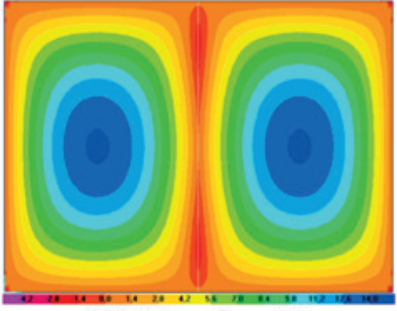

(d) $\mathrm{M}_{11}: \mathrm{d}=40$

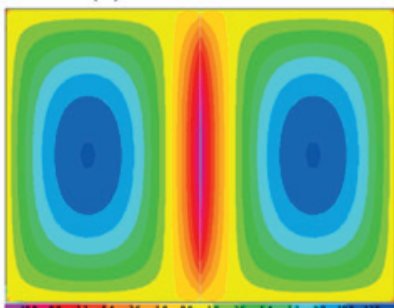

(g) $M_{11}: d=60$

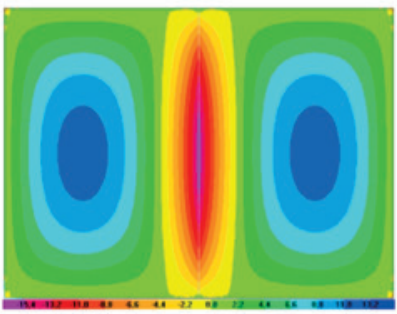

(j) $\mathrm{M}_{11}: \mathrm{d}=80$

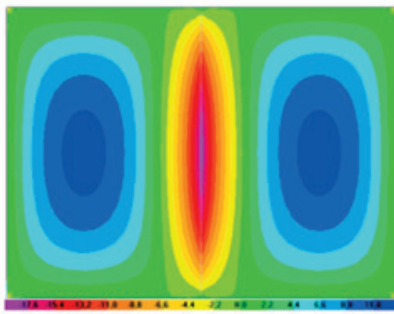

(m) $\mathrm{M}_{11}: \mathrm{d}=100$

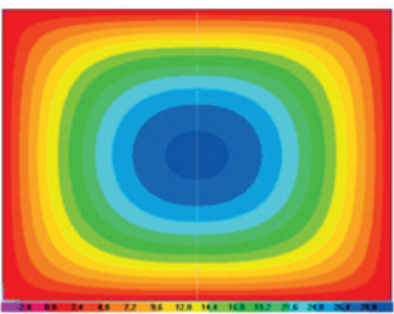

(b) $\mathrm{M}_{22}: \mathrm{d}=15$

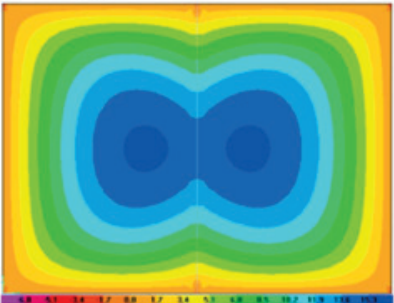

(e) $\mathrm{M}_{22}: \mathrm{d}=40$

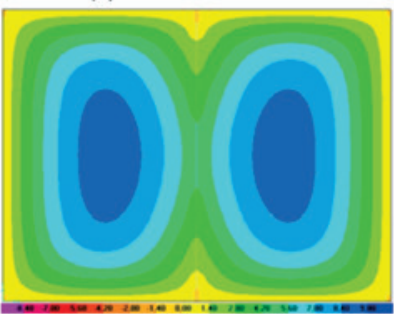

(h) $\mathrm{M}_{22}: \mathrm{d}=60$

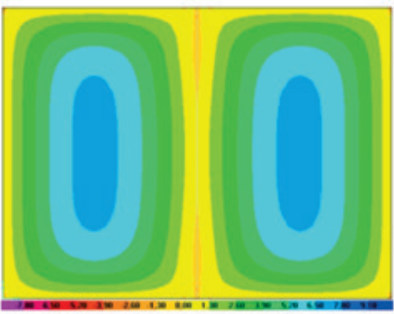

(k) $\mathrm{M}_{22}: \mathrm{d}=80$

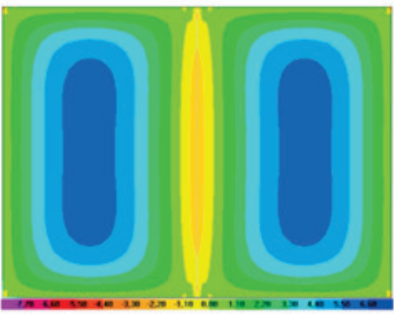

(n) $\mathrm{M}_{22}: \mathrm{d}=100$

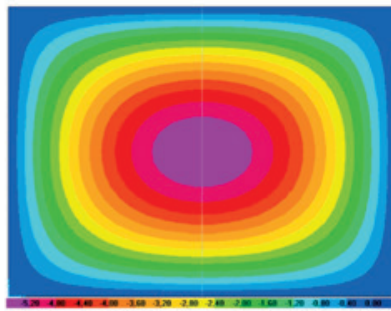

(c) Displacement: $\mathrm{d}=15$

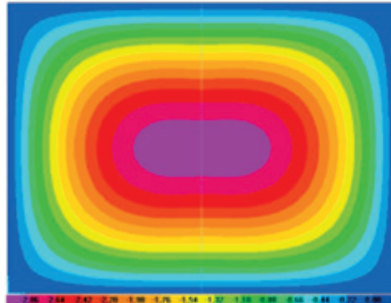

(f) Displacement: $\mathrm{d}=40$

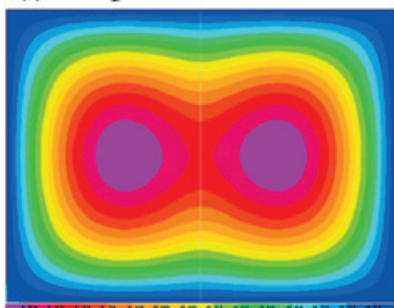

(i) Displacement: $d=60$

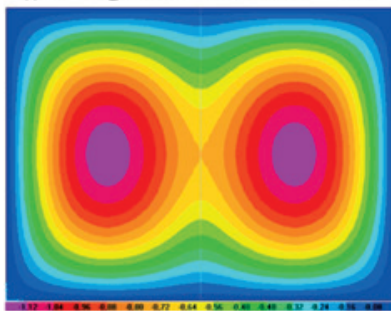

(l) Displacement: $\mathrm{d}=80$

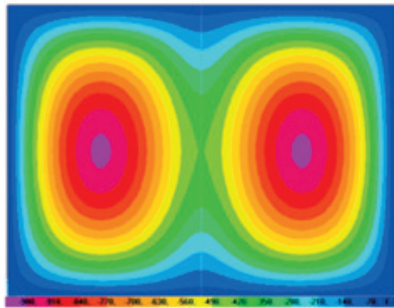

(o) Displacement: $\mathrm{d}=100$ 
model and the tables in Figure 4 for the condition of $\mathrm{V}_{4}$ practically not deformable is because the results obtained by FEM are the maximum values of $L_{1}$, which do not correspond to the center of the slab, while the Czerny results are in the center. To show that when $\mathrm{I}_{\mathrm{v} 4} \leq 0.187$ the results of FEM and Czerny are virtually equal in the center of $L_{1}$, the Figure 5 was elaborated. Only this figure presents the results to the center of $L_{1}$.

Both in Figure 4 and Figure 5 it can be seen the formation of a plateau when $\mathrm{V}_{4}$ has the height equal to the thickness of the slab, i.e. $d=h$. For this condition, which results in $I_{v 4}=34.021$, the plate presents the configuration of just one slab with dimension equal to $8 \times 6 \mathrm{~m}$. The positive bending moments $M x$ and My result in $\operatorname{Im}_{x}=10.06$ and $\operatorname{Im}_{y}=6.50$ indexes, respectively, for all thicknesses of the slabs. Thus, this figures allow the complete the study of the variation of the positive bending moments since the condition of $\mathrm{V}_{4}$ non deformable until $d=h$.

With this data it is possible to answer the following question: what is the error/difference associated with the non-consideration of flexibility and/or deformability of massive slabs, between the use of tables and FEM?

The answer is obtained with the help of Figure 6, which lists the results obtained by FEM and Czerny for the positive bending moments (a) and negative (b) from the plate. It is noticed that, for the configuration of greater rigidity of the plate the relationship between the results obtained by FEM and Czerny is very close to one for $\mathrm{M}_{\mathrm{x}}$ and $\mathrm{M}_{\mathrm{y}}$, and tends to one for $\mathrm{M}_{\mathrm{xe}}$.

For the latter, from $\mathrm{I}_{\mathrm{v} 4} \leq 0.187$ there is no way to relate the results because the bending moment between the slabs becomes positive, as can be seen in Figure 7 and thus, the plate works as if it was composed of only a slab supported by the edge beams $\left(V_{1}, V_{2}\right.$, $V_{3}$ and $V_{5}$ ). In this situation, beam $V_{4}$ fails to work as a support for $L_{1}$ and $L_{2}$ slabs and assumes the function of a slab rib.

Figure 8 shows the variation of displacements and efforts, $x\left(M_{11}\right)$ and $y\left(M_{22}\right)$ direction, as it reduces stiffness of V4, which causes the increase of the positive bending moments, increase of displacements and decrease of the $\mathrm{M}_{\mathrm{xe}}$. An important aspect about the negative moments is that these are not uniform along the continuous edge between the two slabs, as evidence the Figure 7 and Figure 8(a, d, g, $\mathrm{j}, \mathrm{m})$. These checks on the bending moments are important for the analysis of the plate since, when adopting an analysis that does not take into account the flexible behavior of the supports, it should be ensured that the beams have bending stiffness. The representation of the bending moments and displacements with tracks of isovalues, Figure 8, allows the visualization of distribution of efforts, as it reduces the stickiness of $V_{4}$. It is possible to verify that the point of maximum displacement of $\mathrm{L}_{1}$ is not in the center of the slab, and when $\mathrm{V}_{4}$ is very flexible $\left(I_{v 4}>0.4181\right)$ this occurs in the center of the beam, with the same value for $L_{1}, L_{2}$ and $V_{4}$, i.e., the point of maximum displacement for all elements coincides in the same place.

The immediate displacement $\left(a_{t, 0}=\delta\right.$ ), which is the maximum elastic displacement from the plate $\left(\mathrm{L}_{1}\right.$ and $\left.\mathrm{V}_{4}\right)$ is presented in Figure $9(a)$. The highest values of displacements correspond to the configuration of less rigidity, and these displacements present nonlinear decreasing behavior as the plate increases its rigidity. This behavior is also evidenced in other studies [2], [5] and [6]. Figure 9 (b) shows the total displacement of $\mathrm{L}_{1}\left(a_{t, \infty}=\delta_{t}\right)$, calculated according to equation (9), for an infinite time ( $t \leq 70$ months) and loading applied in $t_{0}=6$ months [9].

\section{Figure 9 - (a) Immediate displacement: LI and V4; (b) Final displacement: LI}

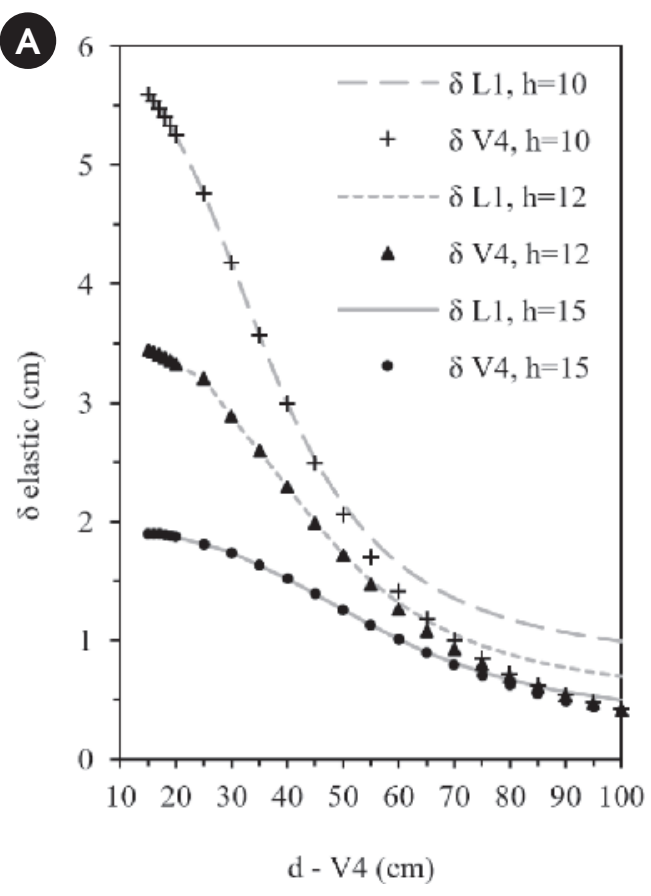

B

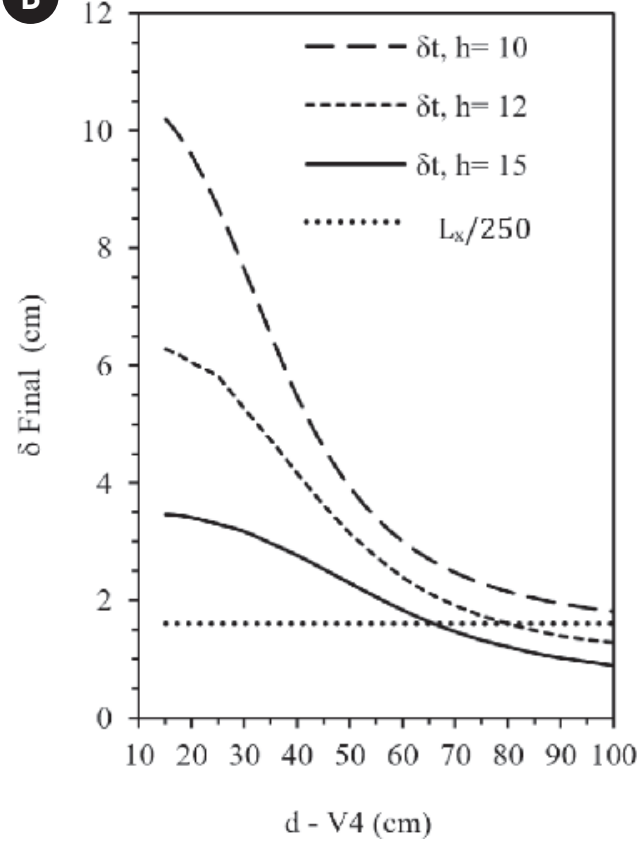


With this criterion, the displacements are multiplied by $\left(1+\alpha_{f}\right)$ with $\alpha_{f}=0.82$, to consider the effect of fluency [9]. Equation (9) should be used for displacements in reinforced concrete structures that have their displacements calculated from equivalent inertia, which presupposes knowledge of the armors. In this theoretical study, in which the armors are not defined, equation (9) was used only as a simplified method to estimate the total displacement.

$$
\delta_{t}=a_{t, \infty}=\left(1+\alpha_{f}\right) a_{t, 0}
$$

The permissible displacement according to [9], concerning the visual sensory acceptability $(I / 250)$, to $L_{1}$ is shown in Figure 9 , in which, "l" is the length of the smallest slab interspace. Therefore, to meet the requirements regarding the excessive deformations of slabs, one must have $\delta_{\lim } \leq 1.6 \mathrm{~cm}$. It turns out that, for $h=10 \mathrm{~cm}$ the normative limit is not accomplished to any value of $d$. For $h=12 \mathrm{~cm}$ and $\mathrm{d} \geq 80 \mathrm{~cm}$ this condition is met and with $h=15 \mathrm{~cm}$ the condition is met for $d \geq 70 \mathrm{~cm}$. It is important to remember that one can appeal to the use of shoring to decrease the final displacement.

\subsection{Dynamic analysis}

The results of the dynamic analysis, as the values of the fundamental frequency $\left(f_{1}\right)$, are displayed in Figure 10. Those results confirm that, the more flexible the structure is the lower the value of $f_{1}$ with non-linear variation will be. This behavior was expected, since from equation (6) it can be seen that the increased

Figure 10 - Fundamental frequency of vibration

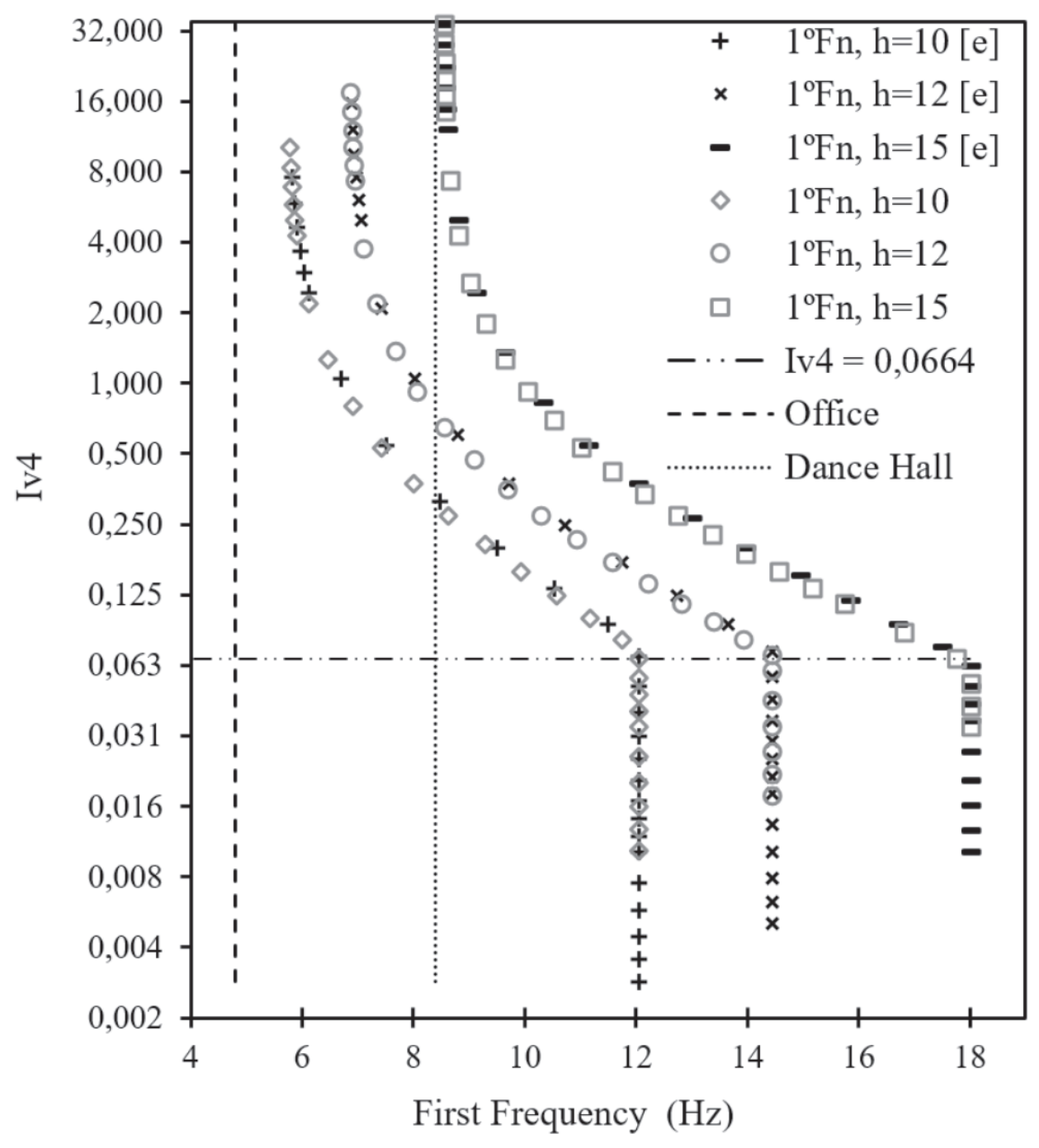


rigidity of the structure will result in higher values of eigenvalues (frequencies).

The frequency values of the second and the third vibration mode are presented in Figure 11 and Figure 12 respectively. It is noticed that in a manner similar to the analysis of the efforts, displacements and frequencies of the first mode, a nonlinear variation of the values of these frequencies is noticed for the second and the third modes.

The dynamic properties also are also affected when considering " $e "$. With equation (1) it is determined that the increased rigidity of the structure without increasing the mass of the same, causes an increase in frequencies of vibration. The increase of the sections of the structural elements causes a gain of rigidity to the system and at the same time adds more mass to this system.

What poses the following question: to what extent the values of $h$ and $d\left(I_{v 4}\right.$ values) can be increased and thus cause an increase in fundamental frequency of vibration $f_{1}$ ?

The answer is obtained by the analysis of Figure 10 to Figure 13. With Figure 10 it is verified that for the $I_{v 4}$ relationships smaller than $0.0664(h=10), 0.0588(h=12)$ and $0.0523(h=15)$ the fundamental frequency $\left(f_{1}\right)$ becomes constant, i.e. does not show variation with the increase of $\boldsymbol{d}$. For the second vibration mode $\left(f_{2}\right)$, Figure 11 , a contrary behavior is shown, i.e. while $f_{1}$ increased $f_{2}$ remains constant and when $f_{1}$ becomes constant the values of $f_{2}$ increase.

The third mode presents a level of constant values for frequencies with limits related to this baseline, close to the first mode found. The participation of the third mode in the displacements in the vertical direction is practically nil.

The reason for this behavior can be explained with the help of Figure 13 , which shows the variation of the modal participation factor ( $M p f)$, with values in module (a) and considering the signal + or -, which depends on the parameterization mode without any significance to this study. In the figure it is observed that for $I_{v 4}>0.0664$ the first vibration mode will have a higher $M p f$ and when $I_{v 4} \leq 0.0664$ the second mode will have a greater $M p f$. This means that when $V_{4}$ has great bending stiffness the second mode shall mobilize more mass according to the vertical direction ( $Z$ global axis) instead of the first mode.

In relation to the condition of meeting the vibration limit state for use of the plate such as "Office", the structure is acceptable for any $I_{v 4}$ relationship under study (Figure 10) since the minimum value of the first vibration frequency required by the standard should be $f_{1}>4.8 \mathrm{~Hz}$ (Table 1 ). In case of destination of the plate as

\section{Figure 11 - Vibration frequency: second mode}

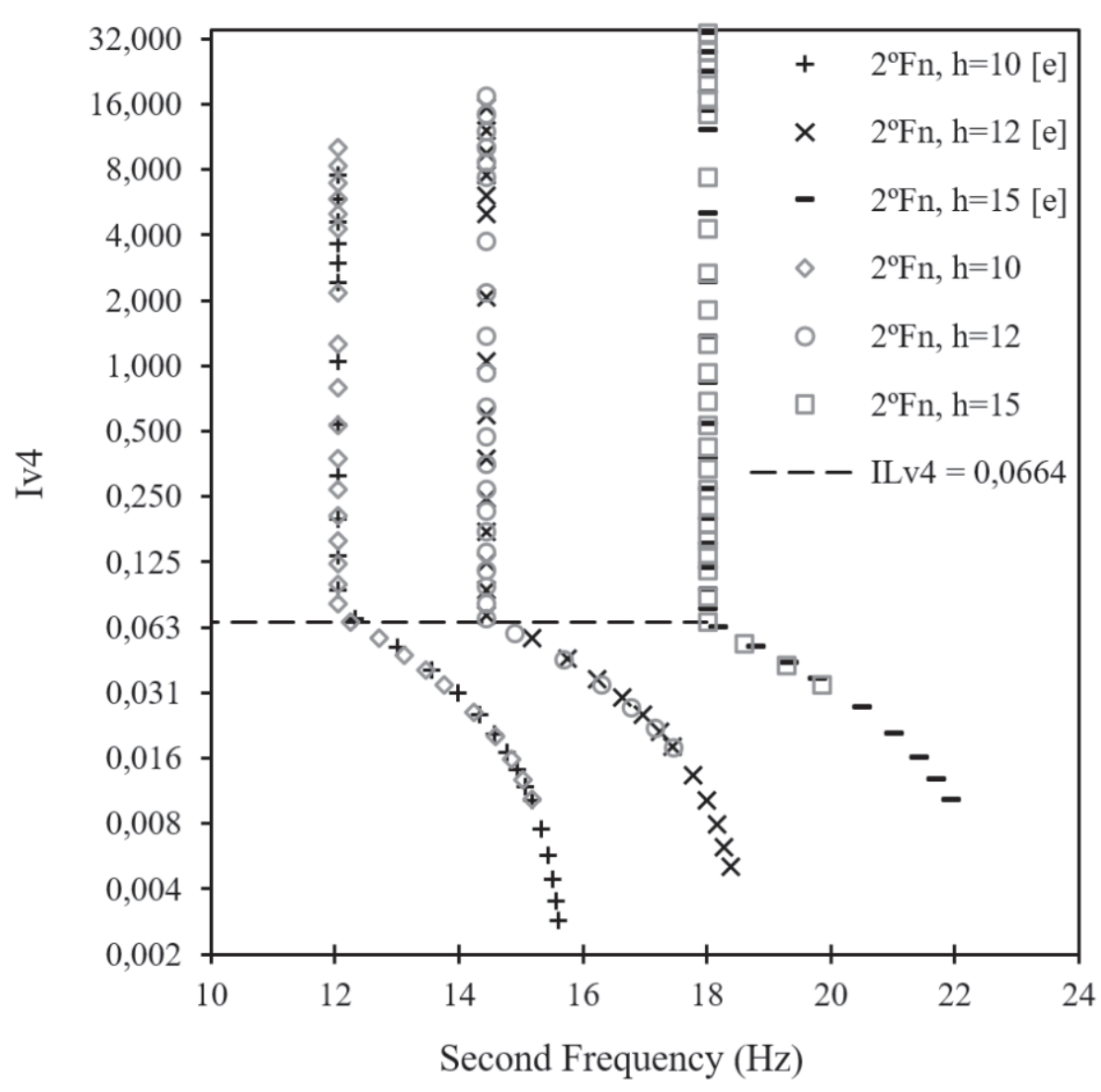


Figure 12 - Vibration frequency: third mode

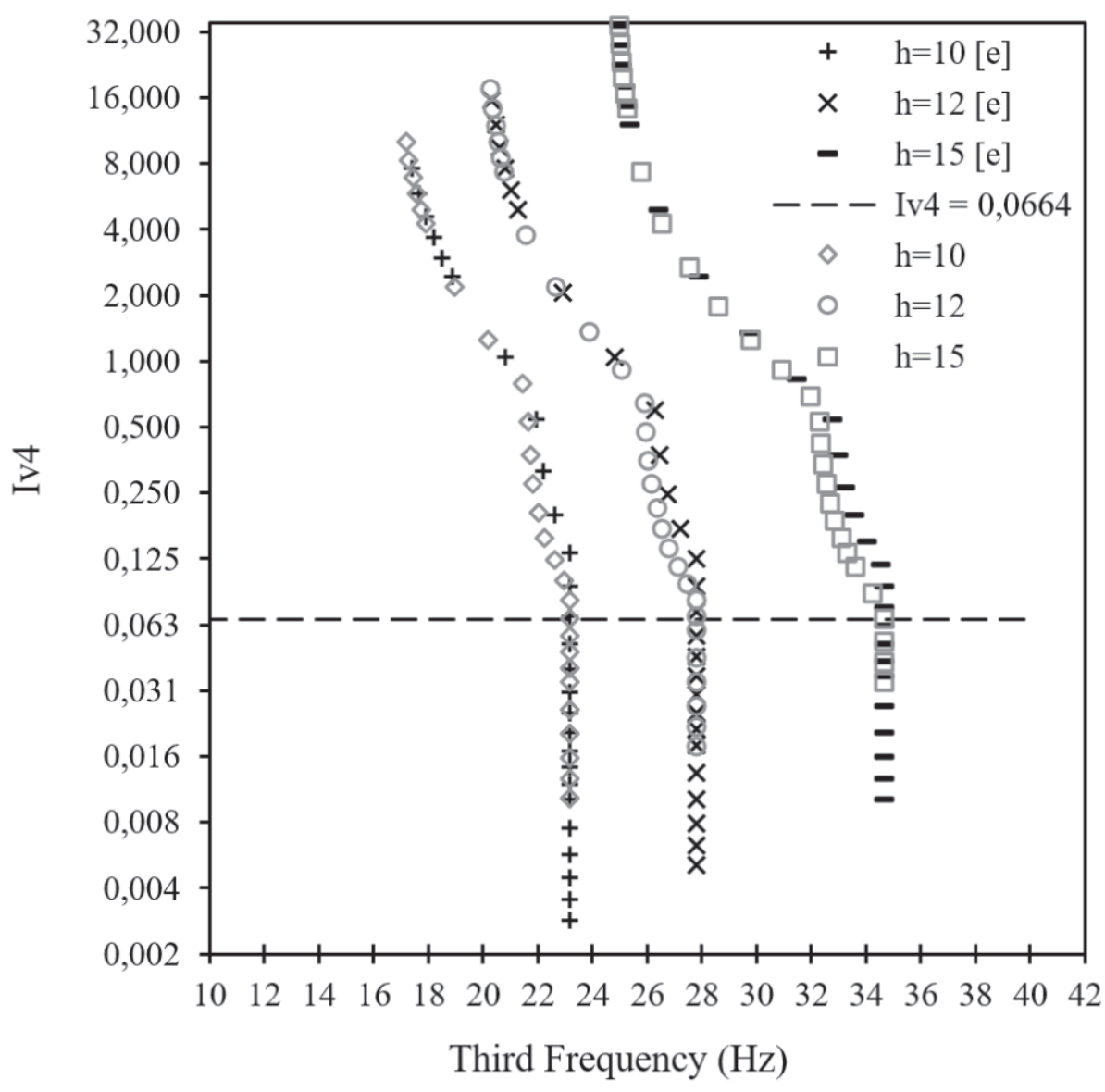

"Dance Hall" ( $f_{1}>8.4 \mathrm{~Hz}$ ) the requirement is satisfied for all the analyses with $h=15$. When $h=10$ the threshold is met when $d^{3} 50 \mathrm{~cm}$ and for $h=12$ with $\mathrm{d} \geq 45 \mathrm{~cm}$ taking into account the values of first frequency vibration mode. This comments are about the results without consideration of eccentricity.

About the limits mentioned in reference [9] for static and dynamic properties, Figure 9 and Figure 10 show that the variation of the displacements and frequencies occurs in a manner contrary to each other. This means to say that, as it reduces the stiffness of beam $V_{4}$ the frequency values decrease and the displacements increase. It should be noted that the increase in rigidity of the plate is beneficial to the project, since the general goal is to have smaller displacements and higher frequencies. Therefore, it appears that for $h=10$ and $h=12$ and a use as "Dance Hall" first we will reach the static limit and after the dynamic limit, as the stiffness of the plate is reduced. For using as "Office" all settings of geometries attend the dynamic limit, as can be seen in Figure 14.

This relationship between the static and the dynamic response is very important because to perform only static analysis of the floor it is possible to know if the dynamic limit was reached or not.

The first three vibration modes of the plate associated with the slab thickness $h=12$ are presented in Figure 15. From the analysis of the first three modes it turns out that these are vertical modes and that the modes setting changes when the rigidity of beam $V_{4}$ is increased.

\section{Conclusions}

It was found that the rigidity of the support beams of massive slabs has fundamental importance and contribution in the stiffness of the plate and, consequently, modifies the static response and dynamic properties as well as how it does this modification.

It turns out that the increased flexibility of the beams of the plate can change the direction of the greatest bending moments acting on the slab. This direction depends on the relationship between rigidity of slab and beam, and so, can be either in the direction of the smaller length or in the direction of the greater length. This behavior is related to the variation of the negative bending moment. Requesting efforts are distributed according to the relative stiffness between the elements that make up the structure, in case slabs and beams. The effort always will tend to concentrate in regions that have greater stiffness. 
It was demonstrated that by using the traditional calculation tables of slabs for the determination of the stresses and displacements, it should be ensured that the support beams have significantly higher bending stiffness than the slab. If that rigidity cannot be ensured, it was shown the difference due to the flexible behavior of the support beams. It was shown that the negative bending moment of the slabs is not uniform throughout the plate of continuity between slabs. So, when using the maximum value of this effort, for the entire edge, one can get a safe sizing, however, it may not be a cost-effective solution.

The dimensionless index $I_{s b}\left(I_{v 4}\right)$ which relates the flexibility between slab and beam, shows efficient representation of the results of the static response and dynamic properties, since these results may be displayed without the need to introduce explicitly the values of slab thickness and height of beams, of which were carried out the analyses, although the findings are specific to the model adopted. With the $I_{s b}$ it was found to be possible to show the variation of the modal participation factor and analyze, for each relationship, which is the vibration mode that is mobilizing more mass for the vertical displacements of the slabs. For vibration frequencies identified levels of values, and this result shows that, for certain $I_{s b}$ relations, it will not be the first mode that will mobilize more mass according to the vertical direction, but other. These is the principal contribution of this paper.

The methodology adopted for this study is appropriate, since it is simple, it does not require great effort and can be easily implemented in the algorithms of structures analysis softwares. The method also takes advantage over more complex methods, such as the Plate-Frame Model (PFM) and the Shell-Frame Model (SFM) [8].

A realistic and accurate modeling, in elastic-linear regime, can be held to consider the monolithic behavior between slab and beam and leverages the behavior of $T$ beams (contribution of the slab compression table). This increased rigidity influences the distribution of internal efforts, stresses, deformations and displacements, as can be verified in reference [16], that used the procedure that considers the inertia of the $\mathrm{T}$ section in relation to the geometric center of the same, with consideration of the influence of Poisson coefficient on the compression table as proposed by reference [17]. The study in [16] also performed the analysis of which geometric configuration would be the most appropriate and for this purpose a cost analysis of steel and concrete was performed.

\section{Figure 13 - (a) Mpf (module); (b) considering the + and - sign}
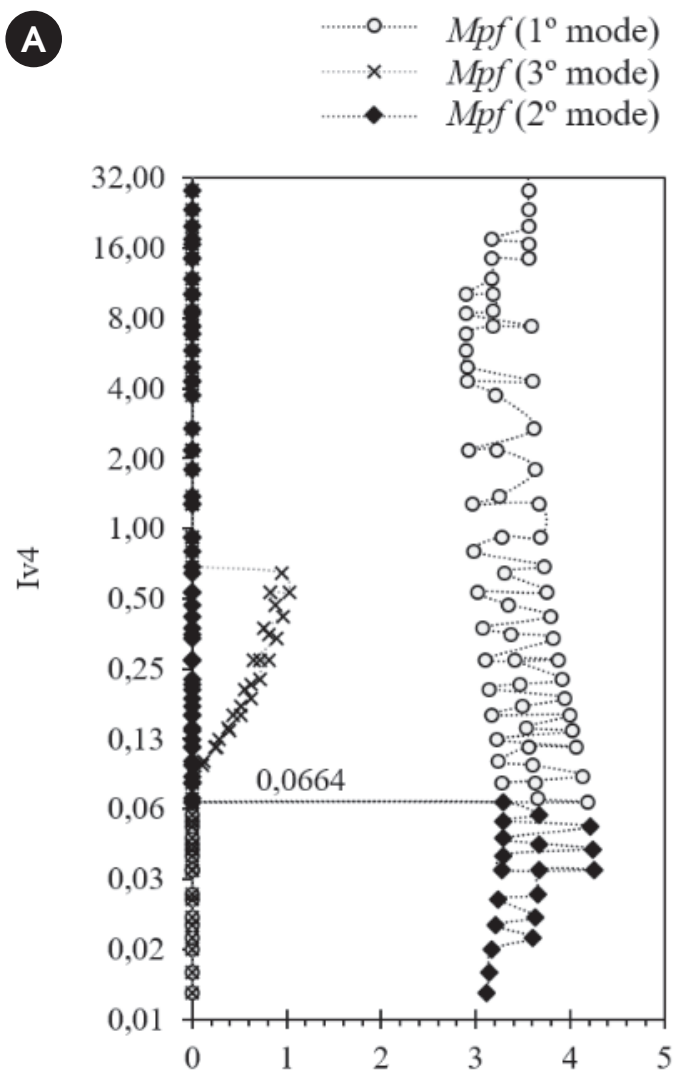

(a) $\operatorname{MPF}\left(\mathrm{kNs}^{2}\right)$
B

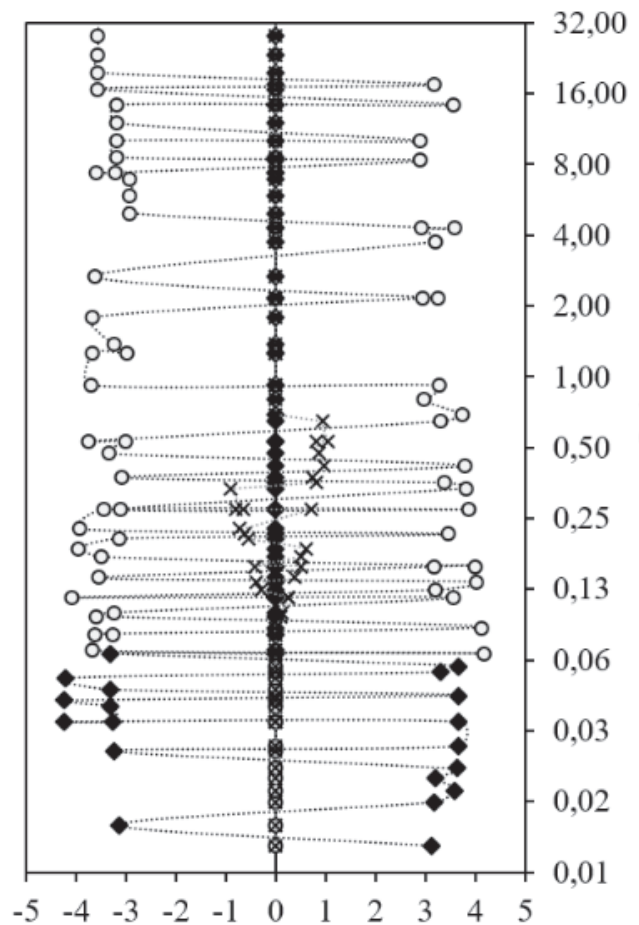

(b) MPF $\left(\mathrm{kNs}^{2}\right)$ 
It should be noted that these checks are related to the plate used and the criteria established for obtaining the results.

\section{Acknowledgments}

The authors thank the Conselho Nacional de Desenvolvimento Científico e Tecnológico (CNPq), the Federal University of Santa Catarina (UFSC), the Postgraduate Program in Civil Engineering (PPGEC-UFSC) and the Federal Technological University of Paraná (UTFPR).

\section{References}

[1] Mazzilli, A. R. P. (1988). Influence of deformability of the support beams in the calculation of building structures. Dissertation (in Portuguese), University of Sao Paulo, Brazil.

[2] Mazzilli, A. R. P. (1995). Influence the flexibility of the beams and slabs on the efforts of reinforced concrete structures. Thesis (in Portuguese), University of Sao Paulo, Brazil.

[3] Araújo, J. M. (2008). Avaliação dos métodos simplificados para cálculo de lajes maciças apoiadas em vigas flexíveis. Teoria e Prática na Engenharia Civil 12: 1-11.

[4] Araújo, J. M. (2009). Método simplificado para cálculo de lajes maciças apoiadas em vigas flexíveis: validação por meio da análise não linear. Teoria e Prática na Engenharia Civil 14: 71-81

[5] Paula, W. C. (2007). Structural behavior of ribbed reinforced concrete slabs based on the use of ANSYS software. Dis- sertation (in Portuguese), State University of Rio de Janeiro.

[6] Leite, M. R. S., Silva, J. G. S., Tavares, M. E. N., Soeiro, F. J. C. P. (2010). Estudo do comportamento estático e dinâmico de lajes nervuradas de concreto armado. Mecánica Computacional Vol XXIX 9929-9937 (Buenos Aires).

[7] Amorim, A. B. A., Lopes, Fernanda R. C., Silva, J. G. S., Tavares, M. E. N. (2010) Considerações de Projeto Sobre a Análise de Vibrações de Sistemas Estruturais de Pisos de Concreto Armado. In: Engenharia Estudo e Pesquisa 1: 56-67.

[8] Tangwongchai, S., Anwar, N., Chucheepsakul, S. (2011). Flexural responses of concrete slab over flexible girders through FEA-based parametric evaluation. KSCE Journal of Civil Engineering 6: 1057-1065.

[9] ABNT NBR 6118. (2014). Projeto de estruturas de concreto - Procedimento.

[10] Csi. (2009). SAP2000 Basic Analysis Reference.

[11] Hamedani, S. J., Khedmati, M. R., Azkat, S. (2012). Vibration analysis of stiffened plates using finite element method. Latin American Journal of Solids and Structures 1: 1-20.

[12] Clough, R. W., Penzien, J. (2003). Dynamics of Structures, McGraw-Hill (New York).

[13] Lima, S. S., Santos, S. H. C. (2008). Análise Dinâmica das Estruturas, Ciência Moderna Ltda, (Rio de Janeiro)

[14] Chopra, A. K. (1995). Dynamics of Structures: Theory and applications to earthquake engineering, Prentice Hall (New Jersey).

[15] Meirovitch, L. (2000). Fundamentals of vibrations, McGrawHill (Boston).

\section{Figure 14 - Final displacement $L_{1}$ and first frequency}

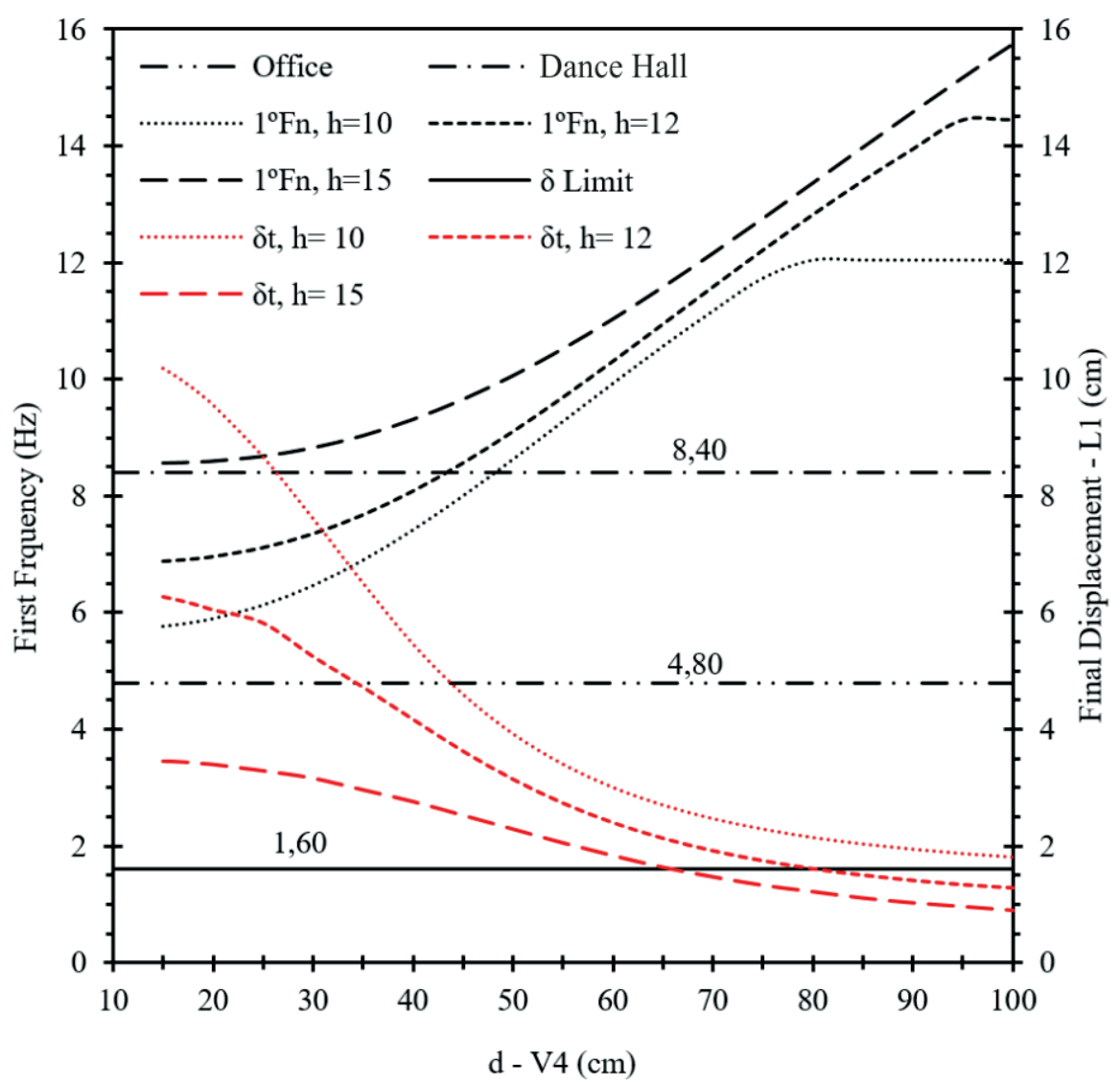


[16] Bueno, J. R. (2013). Influence of flexibility of support beams in project of solid slabs of armed concrete. Dissertation (in Portuguese), Federal University of Santa Catarina, Brazil.
[17] Kennedy, J. B., Bali, S. K. (1979). Rigidities of concrete waffle-type slab structures. Canadian Journal of Civil Engineering 1: 65-74.

Figure 15 - Vibration modes to slabs with $\mathrm{h}=12 \mathrm{~cm}$

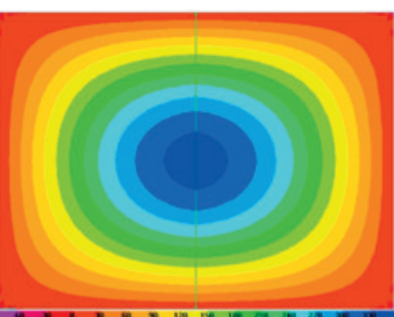

(a) $1^{\circ}$ mode: $d=15$

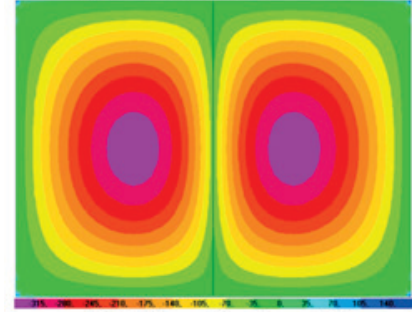

(d) $1^{\circ}$ mode: $d=50$

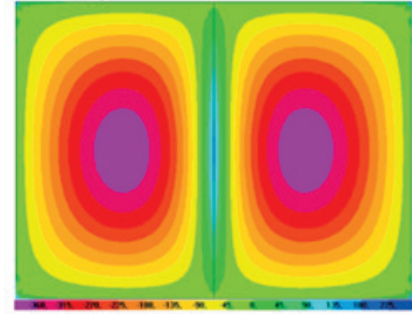

(g) $1^{\circ}$ mode: $d=60$

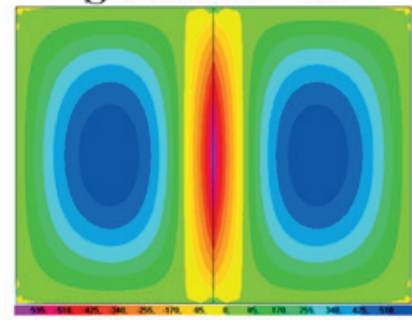

(j) $1^{\circ}$ mode: $d=80$

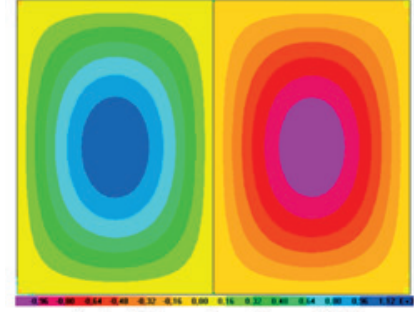

(m) $1^{\circ}$ mode: $d=100$

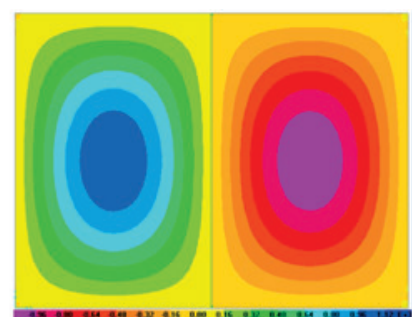

(b) $2^{\circ}$ mode: $d=15$

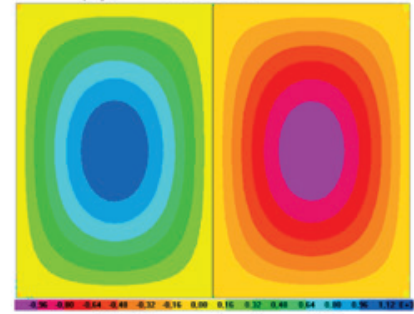

(e) $2^{\circ}$ mode: $d=50$

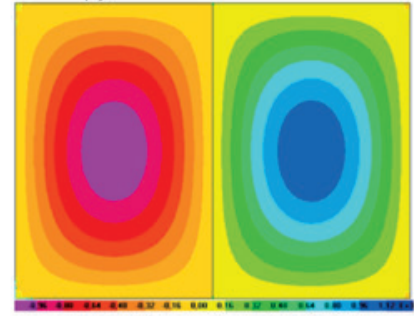

(b) $2^{\circ}$ mode: $d=60$

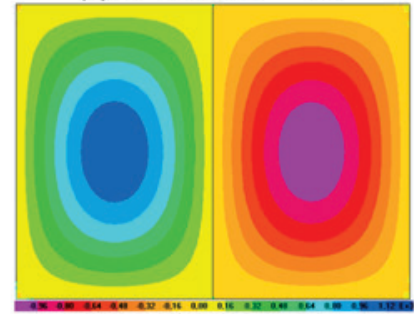

(k) $2^{\circ}$ mode: $d=80$

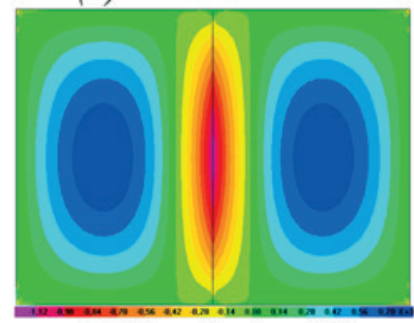

(n) $2^{\circ}$ mode: $d=100$

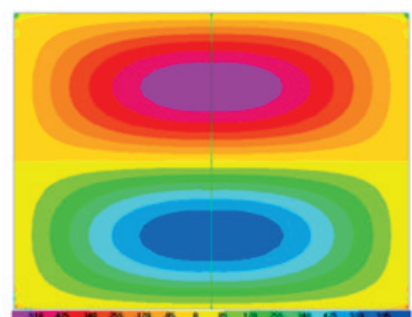

(c) $3^{\circ}$ mode: $d=15$

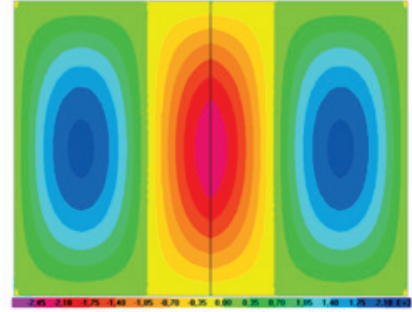

(f) $3^{\circ}$ mode: $d=50$

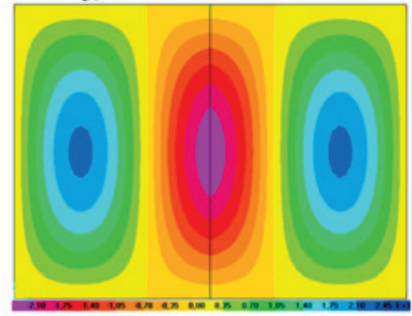

(i) $3^{\circ}$ mode: $d=60$

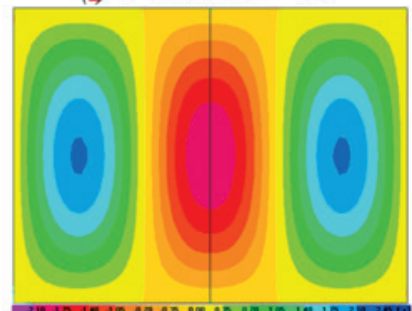

(l) $3^{\circ}$ mode: $d=80$

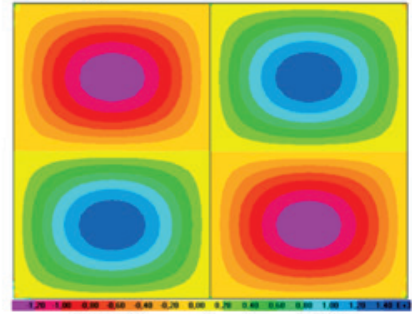

(o) $3^{\circ}$ mode: $d=100$ 